\section{CM2 antigen, a potential novel molecule participating in glucuronide transport on rat hepatocyte canalicular membrane}

\author{
L. Wang, ${ }^{1}$ J. Wang, ${ }^{1,2}$ X. Zhou, ${ }^{1}$ J. Li, ${ }^{1}$ \\ Y. Shi, ${ }^{1}$ Z. Han, ${ }^{1}$ X. Wang, ${ }^{1}$ S. Li, ${ }^{1}$ Z. Yang, ${ }^{1}$ \\ R. Wang, ${ }^{2}$ D. Fan, ${ }^{1}$ Y. Han ${ }^{1}$ \\ 'Division of Hepatology, Xijing Hospital \\ of Digestive Diseases, The Fourth \\ Military Medical University, Xi'an, \\ Shaanxi Province, China \\ 2Department of Pathology, The Fourth \\ Military Medical University, Xi'an, \\ Shaanxi Province, China
}

\section{Abstract}

The polarized molecules predominately distributing at hepatocyte canalicular surface play a vital role in disclosing the process of bile formation and etiopathogenisis of cholestatic live diseases. Therefore, it is important to find novel polarized molecules on hepatocyte canalicular membrane. In the present study, canalicular membrane vesicles (CMVs) isolated from rat hepatocyte by density gradient centrifugation were used as immunogens to produce hybridoma and 46 strains of monoclonal antibodies (mAb) against CMVs were obtained. With a series of morphological assay methods, including immunohistochemistry, immunofluorescence and immuno-electron microscope, the antigens recognized by canalicular mAb1 (CM1) and canalicular mAb2 (CM2) were confirmed to predominately distribute at hepatocyte canalicular membrane. Transport activity assay revealed that CM2 could inhibit ATP-dependent E217 $\beta$ G uptake of rat hepatocyte CMVs. Meanwhile, Western blotting analysis showed that the molecular mass of CM2 antigen was approximately $110 \mathrm{kDa}$, which was much less than Mr 180kDa of multidrug resistance-associated protein 2 (MRP2) involved in glucuronide transport. These data indicated that CM2 antigen might be a potential novel molecule participating in glucuronide transport on the hepatocyte canalicular membrane.

\section{Introduction}

Hepatocyte exhibits a striking polarity with three distinct membrane surfaces, which are sinusoidal, canalicular and lateral surfaces.
Different surface represents the unique morphological and functional characteristics. Bile secretion is mediated by many polarized molecules on hepatocyte canalicular membrane, which is characterized by numerous microvilli and has special transport activities. ${ }^{1}$

So far, many polarized molecules including enzymes, receptors, transporters and exchangers, are identified to specifically localize to hepatocyte canalicular membrane. ${ }^{2}$ These polarized molecules play important roles in various liver diseases, especially in cholestatic liver diseases. Due to hepatocyte damage, liver plasma membrane fragments are released into the circulation and several canalicular membrane specific enzymes in serum, such as glutamyltranspeptidase $(\gamma$-GT), alkaline phosphatase (ALP), leucine aminopeptidase (LAP) and $5^{\prime}$-nucleotidase $\left(5^{\prime}-\mathrm{Nu}\right)$, have been deemed as clinical diagnostic markers. ${ }^{3,4}$ In addition, the absence or mutation of some transporters could directly lead to bile metabolism disorders. Dubin-Johnson syndrome, an autosomal recessive cholestatic disorder, results from the mutation of the multidrug resistance-associated protein 2 (MRP2) with the absence of MRP2 protein at hepatocyte canalicular membrane..$^{5-7}$ Mutations in code sequence of the familial intrahepatic cholestasis-1 (FIC1) contribute to Byler's disease, progressive familial intrahepatic cholestasis (PFIC) type 1, with severe and progressive intrahepatic cholestasis. ${ }^{8}$ Besides, the lower expression, decreased immunoreactivities and defective transport activities of chloride-bicarbonate anion exchangers (AE2) could be associated with primary biliary cirrhosis (PBC) disease. $^{9}$

Therefore, the present study aimed to find novel molecules distributing at the hepatocyte canalicular membrane with hybridoma technology and functional screening.

\section{Materials and Methods}

\section{Isolation and idenfication of rat canalicular membrane vesicles}

According to the method described previously, ${ }^{10,11}$ canalicular membrane vesicles (CMVs) and sinusoidal membrane vesicles (SMVs) were prepared from Sprague-Dawley rats liver homogenates using density gradient centrifugation method. Vesicles were suspended in 50 $\mathrm{mM}$ Tris/HCl (pH 7.4) buffer containing 250 $\mathrm{mM}$ sucrose and freezed in liquid nitrogen until further use. The morphological and biochemical characteristics of isolated CMVs and SMVs were confirmed by transmission electron microscopy and enzyme assay respectively as described in our published paper. ${ }^{12}$
Correspondence: Dr. Ying Han, State Key Laboratory of Cancer Biology, Institute of Digestive Diseases, Xijing Hospital, The Fourth Military Medical University, No. 127 Changle Western Road, Xi'an, 710032, Shaanxi Province, China.

Tel. +86.29.84771506 - Fax: +86.29.82539041.

E-mail: hanying1@fmmu.edu.cn

Key words: hepatocyte canalicular membrane; glucuronide transport, canalicular mAb2 (CM2); hybridoma technique.

Acknowledgments: this study was supported by the National Natural Science Foundation of China (NO. 30971339, 30971116, 81071873 and 81070326), and the Science and Technology Innovation Project of Shaanxi Province (NO. 2011KTCL03-09).

The authors would like to thank Yongzhan Nie, Taidong Qiao, and Zheng Chen for their technical guidance during the experiment.

Contributions: LW and JW contributed equally to this work.

Received for publication: 4 December 2011.

Accepted for publication: 19 March 2012.

This work is licensed under a Creative Commons Attribution NonCommercial 3.0 License (CC BYNC 3.0).

(C) Copyright L. Wang et al., 2012

Licensee PAGEPress, Italy

European Journal of Histochemistry 2012; 56:e26 doi:10.4081/ejh.2012.e26

Immunization of animals and production of hybridomas

The rat CMVs were used as immunogens to produce hybridoma. In each case, BALB/c mice were immunized with $100 \mu \mathrm{g}$ proteins in comL. Wangplete Freund's adjuvant (Sigma, St. Louis, M0, USA) and boosted twice with 50 $\mu \mathrm{g}$ proteins in incomplete Freund's adjuvant (Sigma) at 3-week intervals. After immunization, serological responses to CMVs were monitored by an enzyme linked immunosorbent assay (ELISA). Selected mice were intravenously boosted with $30 \mu \mathrm{g}$ proteins in phosphate buffered saline (PBS) 3 days before sacrifice. According to the standard hybridoma technique, spleen cells were fused with SP2/0 myeloma cells using polyethylene glycol and hybridomas were cultured in HAT (hypoxanthine, aminopterin and thymidine) selective growth medium. Seven-eight d after fusion, hybridoma cell supernatants were screened with ELISA and immunohistochemistry methods respectively. Positive hybridomas were cloned by limiting dilution.

\section{ELISA}

Ninety-six well ELISA plates (Corning 
Costar Corp., Cambridge, MA, USA) were coated with CMVs $(10 \mu \mathrm{g} / \mathrm{mL}$ of CMVs in $0.05 \mathrm{M}$ bicarbonate buffer, pH 9.6, $100 \mu \mathrm{L} /$ well) overnight at $4^{\circ} \mathrm{C}$. The coated wells were washed with PBS containing $0.05 \%$ Tween-20 (Sigma, PBST) and then blocked with PBS containing $2 \%(\mathrm{w} / \mathrm{v})$ BSA for $2 \mathrm{~h}$ at $37^{\circ} \mathrm{C}$. Hybridoma cell supernatants were added to the wells $(100 \mu \mathrm{L} /$ well) and incubated for $1 \mathrm{~h}$ at $37^{\circ} \mathrm{C}$. After three rinses with PBST, the wells were incubated with 5000 -fold diluted horseradish peroxidase labelled anti-mouse IgG (Zhongshan Corp, Peking, China) for $1 \mathrm{~h}$ at $37^{\circ} \mathrm{C}$. Reaction product was visualized with citric acid solution (pH 9.6) containing 0.5 $\mathrm{mg} / \mathrm{mL}$ ABTS (Sigma) and $2 \mu \mathrm{L} / \mathrm{mL} \mathrm{H}_{2} \mathrm{O}_{2}$ for 10 min at $37^{\circ} \mathrm{C}$. At last, the plates were read at a wave length of $405 \mathrm{~nm}$ on an automatic microplate reader (Model 680, Bio-Rad Lab, Hercules, CA, USA).

\section{Immunohistochemistry}

Sections of paraformaldehyde-fixed and paraffin-embedded rat liver, small intestine, colon and renal tissues were treated with xylene for $30 \mathrm{~min}$ to remove paraffin, rehydrated for 5 min each with $95 \%, 85 \%$, and $75 \%$ ethanol, treated for $15 \mathrm{~min}$ in a microwave oven with $0.05 \mathrm{M}$ glycine- $\mathrm{HCl}$ (pH 7.4) for antigen retrieval, and treated for 20 min with $3 \%$ hydrogen peroxide to eliminate endogenous peroxidase activity. Sections were incubated with $10 \%$ normal goat serum (NGS) for $1 \mathrm{~h}$ at room temperature and then with hybridoma cell supernatant overnight at $4^{\circ} \mathrm{C}$. Sections were rinsed in PBS three times and incubated with horseradish peroxidase labeled goat antimouse IgG (Dako, Glostrup, Denmark) for $1 \mathrm{~h}$ at room temperature. Reaction products were visualized with diaminobenzidine (Maixin-Bio Inc., Fuzhou, China) for 5 min. Sections were counterstained with hematoxylin (Santa Cruz Biotech Inc., Santa Cruz, CA, USA), dehydrated and mounted. Images were obtained under a light microscope (Olympus BX51, Olympus, Japan).

\section{Pre-embedding immunogold-silver cytochemistry}

Pre-embedding immunogold-silver cytochemistry was performed as previously described. ${ }^{13}$ The deeply anesthetized rats were perfused transcardially with $150 \mathrm{~mL}$ warm saline, followed by $500 \mathrm{~mL}$ ice-cold mixture of 4\% paraformaldehyde, $0.05 \%$ glutaraldehyde, and $15 \%(\mathrm{v} / \mathrm{v})$ saturated picric acid in $0.1 \mathrm{M}$ phosphate buffer ( $\mathrm{pH}$ 7.4) for $2 \mathrm{~h}$. The rat liver tissues were removed and postfixed by immersion in the same fixative for $3 \mathrm{~h}$ at $4^{\circ} \mathrm{C}$. Serial liver sections of $50 \mu \mathrm{m}$ thickness were prepared and placed in PBS containing 25\% sucrose and $10 \%$ glycerol for $1 \mathrm{~h}$. After a freeze- thaw treatment, sections were immersed in PBS containing 5\% BSA and 5\% NGS to block nonspecific immunoreactivity, incubated with CM1 or CM2 hybridoma cell supernatant and goat anti-mouse IgG conjugated to $1.4 \mathrm{~nm}$ gold particles at 1:100 dilution (Nanoprobes, Stony Brook, NY, USA). After rinsing, sections were postfixed in $2 \%$ glutaraldehyde and silver enhancement was carried out in the dark with HQ Silver Kit (Nanoprobes). After fixing with $0.5 \%$ osmium tetroxide in $0.1 \mathrm{M}$ phosphate buffer for $1 \mathrm{~h}$, immunolabeled sections were dehydrated in graded ethanol series, then in propyleneoxide, and finally embedded in Epon 812. After mounting the ultra thin sections on mesh grids (six to eight sections/grid), they were counterstained and observed under a JEM-1230 electron microscope (JEOL Ltd., Tokyo, Japan).

\section{Immunofluorescence}

The ice-frozen sections were incubated with CM1 or CM2 hybridoma cell supernatant and anti-CD13 rabbit polyclonal antibody (Santa Cruz Biotech Inc.), then reacted with FITCconjugated goat anti-mouse secondary antibody and tetraethyl rhodamine isothiocyanateconjugated goat anti-rabbit secondary antibody (Santa Cruz Biotech Inc.). Sections were washed before visualization with confocal microscope (Fluoview-FV10i, Olympus Corp., Tokyo, Japan).

\section{Purification and isotype assay of antibody}

High-titer antibody preparation was obtained from the ascites fluid of mice inoculated intraperitoneally with hybridoma cells $\left(2.5 \times 10^{6}\right.$ cells/mouse). The purification of ascites was performed according to the protocol of antibody purification kit (Pierce, Rockford, IL, USA). Protein concentration was determined using the bovine serum albumin (BSA) protein assay kit (Bio-rad Lab, Hercules, CA, USA). The isotype of monoclonal antibody was identified with Amersham mouse monoclonal antibody isotyping kit (HyCult Biotech, Uden, The Netherlands).

\section{Transport activity assay with CMVs}

[3H]17 $\beta$-estradiol-17 $\beta$-D-glucuronide (E217ßG, $55 \mathrm{Ci} / \mathrm{mmol}$ ) was purchased from PerkinElmer Life Science, Inc. (Boston, MA, USA). Transport activity assay was performed using a rapid filtration technique as described previously. ${ }^{14}$ In brief, reaction mixture consisted of transport medium (10 mM Tris-HCl, 250 $\mathrm{mM}$ sucrose, $10 \mathrm{mM} \mathrm{MgCl} 2, \mathrm{pH} 7.4), 2 \times 10^{-3}$ $\mathrm{mCi} / \mathrm{mL}[3 \mathrm{H}]-\mathrm{E} 217 \beta \mathrm{G}, 5 \mathrm{mM}$ ATP, ATP-regenerating system (10 mM creatine phosphate and $100 \mu \mathrm{g} / \mu \mathrm{L}$ creatine phosphokinase) and different concentration of purified CM1 or CM2 antibody $(1,2,5,10,20,50 \mu \mathrm{g} / \mathrm{mL})$. Normal mouse IgG was used as control. Fifteen $\mu \mathrm{L}$ reaction mixture was preincubated at $37^{\circ} \mathrm{C}$ for different time, rapidly mixed with $5 \mu \mathrm{L}$ CMVs suspension (10 $\mu \mathrm{g}$ proteins) and then terminated by adding $1 \mathrm{~mL}$ ice-cold stop solution ( $250 \mathrm{mM}$ sucrose, $0.1 \mathrm{M} \mathrm{NaCl}, 10 \mathrm{mM}$ Tris$\mathrm{HCl}, \mathrm{pH}$ 7.4). The stopped reaction mixture was filtered through a $0.45-\mu \mathrm{m}$ membrane filter (Millipore Corp, Temecula, CA, USA) and then washed twice with $5 \mathrm{~mL}$ stop solution. Radioactivity (dpm) retained on the filter reacted with $50 \mu \mathrm{L}$ scintillation cocktail and was determined in a liquid scintillation counter (LKB 1215, Bromma, Sweden). The ATPdependent uptake was calculated by subtracting dpm values in the absence of ATP from that in the presence of ATP.

\section{Western blot}

The proteins were separated by SDS-PAGE and transferred to the nitrocellulose membrane. Non-specific binding was blocked with TBS buffer (50 mM Tris- $\mathrm{HCl}$ and $150 \mathrm{mM}$ $\mathrm{NaCl})$ containing $10 \%(\mathrm{w} / \mathrm{v})$ skim milk for $2 \mathrm{~h}$ at room temperature. Then, the membrane was incubated with hybridoma culture supernatant overnight at $4^{\circ} \mathrm{C}$, rinsed with TBS containing $0.05 \%$ Tween-20 (TBST) for three times, then followed by incubation with HRPconjugated goat anti mouse IgG (1:2000 dilution) for $2 \mathrm{~h}$. Finally, the membrane was treated with enhanced chemoluminescence reagent (Santa Cruz Biotech Inc.) and exposed to Kodak X-ray film.

\section{Statistical analysis}

All statistical analysis was performed with Student's $t$-test by Statistical SPSS software package (Version 12.0; SPSS Inc., Chicago, IL, USA). Differences were considered statistically different at $\mathrm{P}<0.05$.

\section{Results}

\section{Distribution of CM1 and CM2 anti- gens on rat liver tissues}

With rat CMVs as immunogens to immunize mice and prepare hybridoma cells, we obtained 46 strains of monoclonal antibodies against CMVs by ELISA screening. Immunohistochemistry assay showed that the distribution of only two strains of mAb, termed as canalicular mAb1 (CM1) and canalicular mAb2 (CM2) respectively, were highly distinctive of the hepatocyte canalicular membrane: anastomosing networks of branched channels as well as circular profiles restricted to regions 
between adjacent hepatocytes. At high magnification, staining appeared to be associated either with the luminal cell surface or with intraluminal convoluted particles. There was no sinusoidal plasma membrane or intracellular staining of both CM1 and CM2 (Figure 1). In addition, the CM1 antigen was present in the brush border of interlobular bile duct epithelium (Figure 1A), but CM2 antigen was not (Figure 1D). Immunoglobulin subclass determination results showed that the isotypes of both CM1 and CM2 were comfirmed to be $\operatorname{Ig} \mathrm{G} 2 \mathrm{a} / \mathrm{\kappa}$ type.

\section{Distribution of CM1 and CM2}

antigens on rat small intestine, colon and kidney tissues

As intestine and renal tubular epithelial cells also exhibit a striking polarity, we further explored the distribution of CM1 and CM2 antigens on rat small intestine, colon and kidney tissues. It was shown that $\mathrm{CM} 1$ and $\mathrm{CM} 2$ antigens also specifically expressed on the brush border of small intestine, colon and proximal tubule epithelial cells (Figure 2). However, staining of CM2 antigen on proximal tubule epithelial cells was much less than that of CM1 antigen (Figure $2 \mathrm{C}$,F). In addition, CM2 antigen was positive at vascular endothelial cells (Figure 2F), but CM1 antigen was negative (data not shown).

\section{Subcellular localization of CM1 and CM2 antigens in rat hepatocyte}

To confirm the distribution of CM1 and CM2 antigens in rat hepatocyte canalicular membrane, subcellular localization was further determined by immunofluorescence, immuno-electron microscope and organelle protein quantitative analysis. CD13 exhibited a characteristic of strict distribution on the canalicular membrane of hepatocyte, ${ }^{15}$ so we observed the co-localization of CD13 and CM1 or CM2 antigens by confocal microscopy. The results showed that CM1 or CM2 antigen stained green was completely overlapping with CD13 stained red in the regions between adjacent hepatocytes (Figure 3 A-C, E-G).

Pre-embedding immunogold-silver cytochemistry also demonstrated that CM1 and CM2 antigens were almost entirely restricted to the canalicular membrane and was negative on the sinusoidal or lateral membrane of hepatocytes (Figure $3 \mathrm{D}, \mathrm{H})$. Furthermore, we quantitatively analyzed the expression of CM1 and CM2 antigens in rat hepatocyte CMVs and SMVs by western blot. It showed that either CM1 or CM2 antigens in rat hepatocyte CMVs was much more than that in hepatocyte SMVs (Figure 4A).

\section{Identification and characterization of CM1 and CM2 antigens}

Western blot showed CM1 recognized a sin-
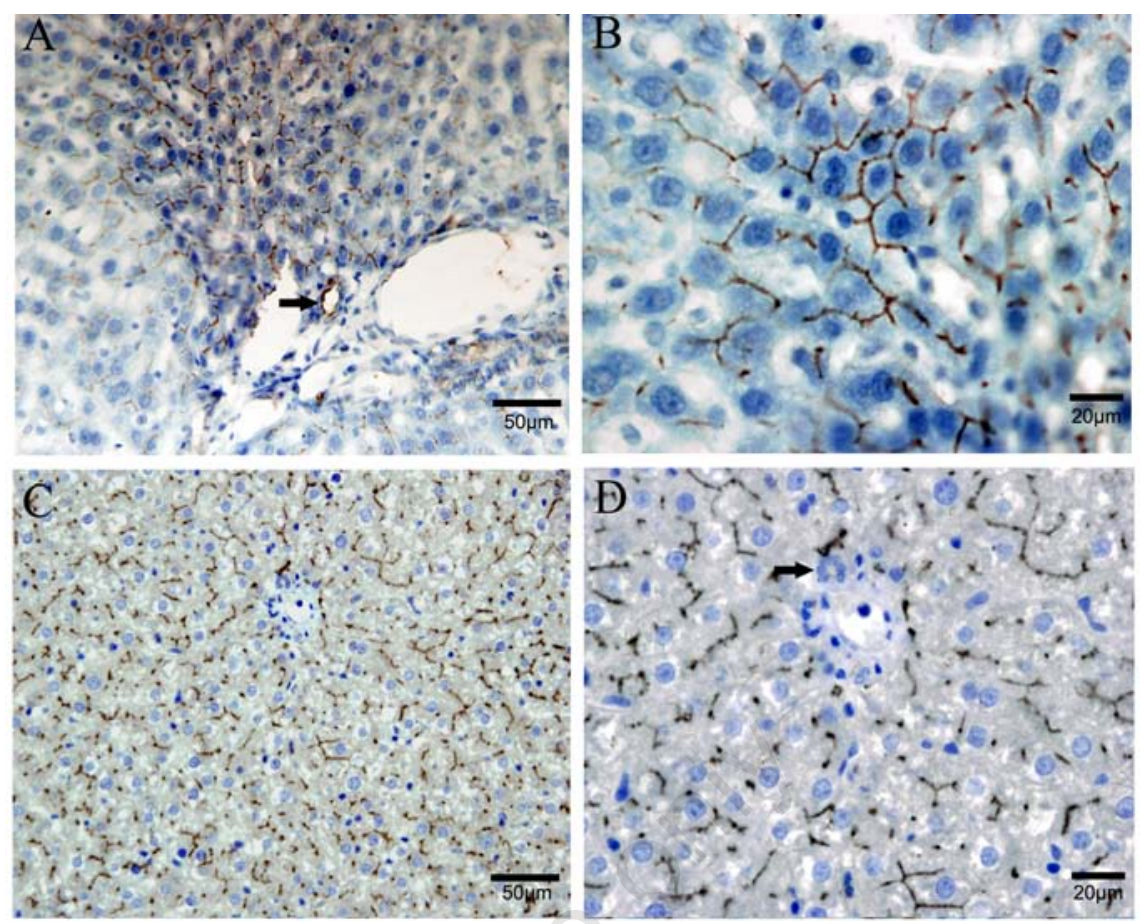

Figure 1. Distribution of CM1 and CM2 antigens on rat liver tissue by immunohistochemistry analysis. A, B) Distribution of CM1 antigen on rat liver tissue. C, D) Distribution of CM2 antigen on rat liver tissue. Both CM1 and CM2 antigens were high positive on the hepatocyte canalicular membrane, but not on sinusoidal membrane or intracellular staining. Brown areas represented positive staining, blue areas represented hematoxylin counterstaining and arrow represented interlobular bile duct.
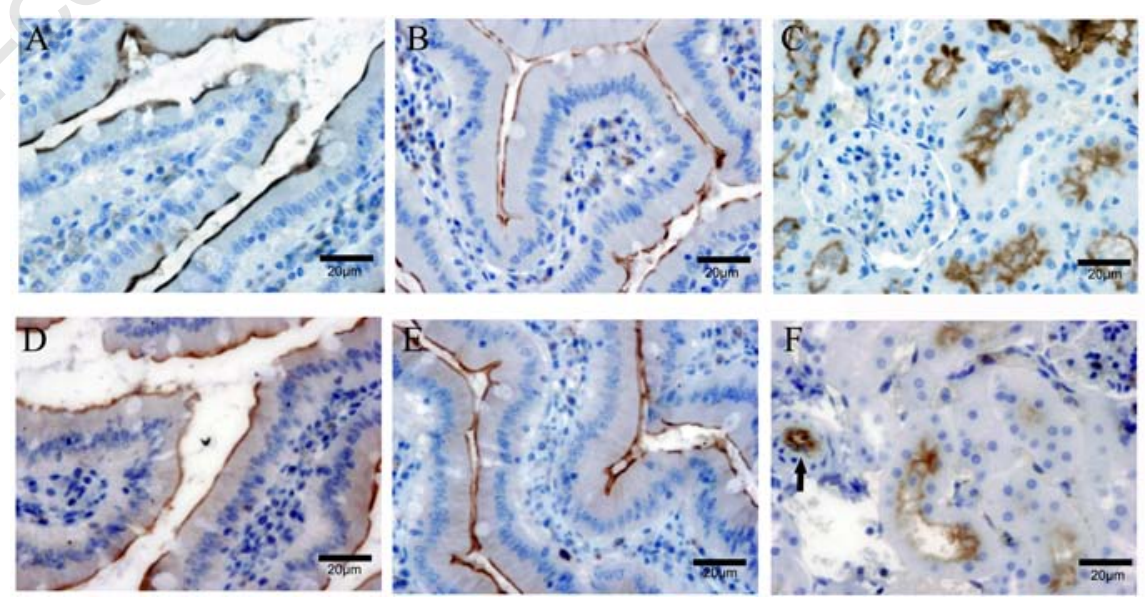

Figure 2. Distribution of CM1 and CM2 antigens in rat small intestine, colon and renal tissues by immunohistochemistry analysis. $\mathrm{A}, \mathrm{B}, \mathrm{C})$ Distribution of $\mathrm{CM} 1$ antigen in rat small intestine, colon and renal tissues respectively; CM1 antigen specifically expressed on the brush border of small intestine, colon and proximal tubule epithelial cells. D, E, F) Distribution of CM2 antigen in rat small intestine, colon and renal tissues respectively; CM2 antigen displayed the same distribution pattern with CM1 antigen in small intestine and colon epithelial cells, but its staining intensity was remarkably less on proximal tubule epithelial cells compared with CM1 antigen; in addition, CM2 antigen was positive at vascular endothelial cells (arrow in F). 
gle protein band with approximately $\mathrm{Mr}$ $140 \mathrm{kDa}$ and CM2 recognized a broad band at Mr $110 \mathrm{kDa}$ with a trailing shoulder (Figure 4A). Furthermore, we evaluated the effect of CM1 or CM2 on glucuronide transport activities of CMVs. It was noted that CM2 but not
CM1 could partially inhibit ATP-dependent E217 $\beta$ G uptake of CMVs (Figure 4B). In addition, CM2 inhibited ATP-dependent E217ßG uptake of CMVs in a concentration-dependent manner and saturatus level was obtained at about $10 \mu \mathrm{g} / \mathrm{mL}$ (Figure 4C).
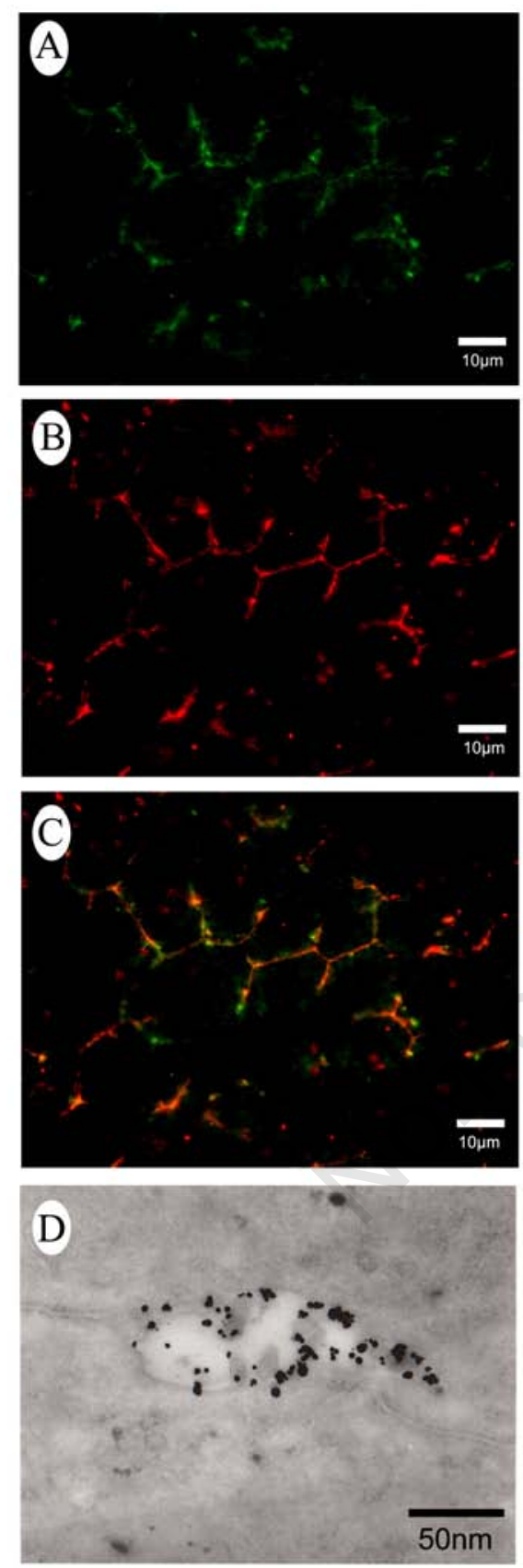
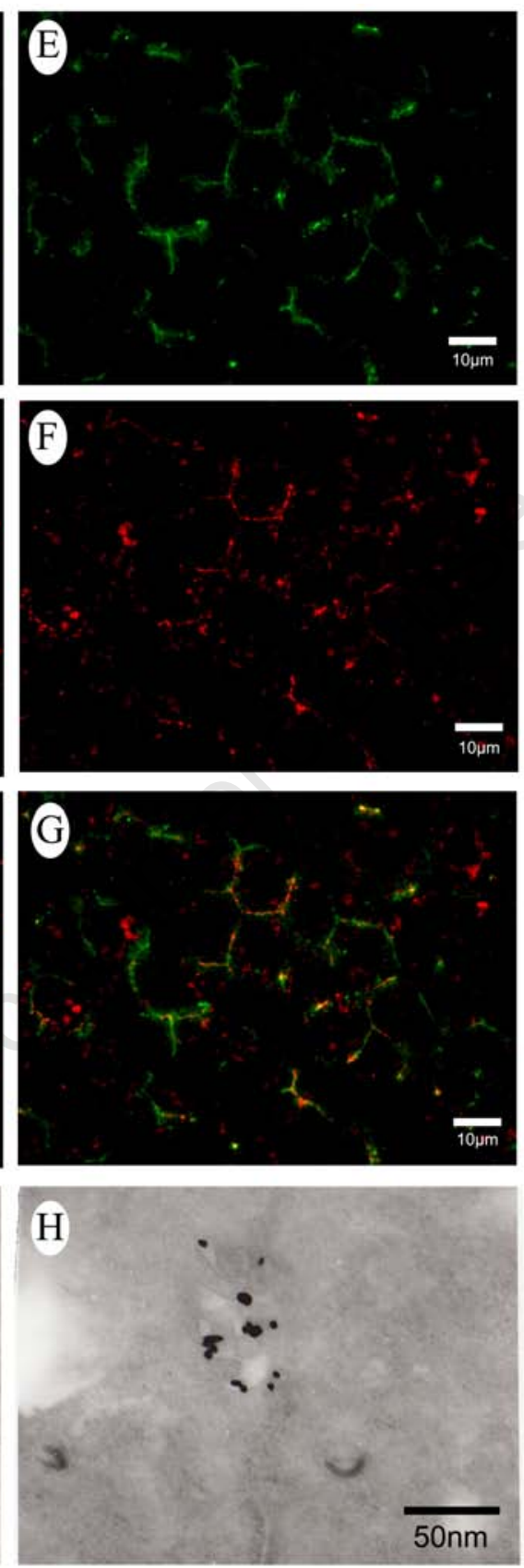

Figure 3. Subcellular localization of CM1 and CM2 antigens in rat hepatocyte. (A-C and E-G) Co-localization of CD13 and CM1 or CM2 antigens by confocal microscopy. Green fluorescence visualized CM1 and CM2 antigens, red fluorescence visualized CD13 (a marker of hepatocyte canalicular membrane), yellow fluorescence visualized co-localization of CD13 and CM1 or CM2 antigens. D, H) CM1 and CM2 antigens localization on hepatocyte canalicular membrane by Pre-embedding immunogold-silver cytochemistry; CM1 and CM2 antigens were almost entirely restricted to the canalicular membrane of hepatocyte; dots represent CM1 and CM2 antigens.
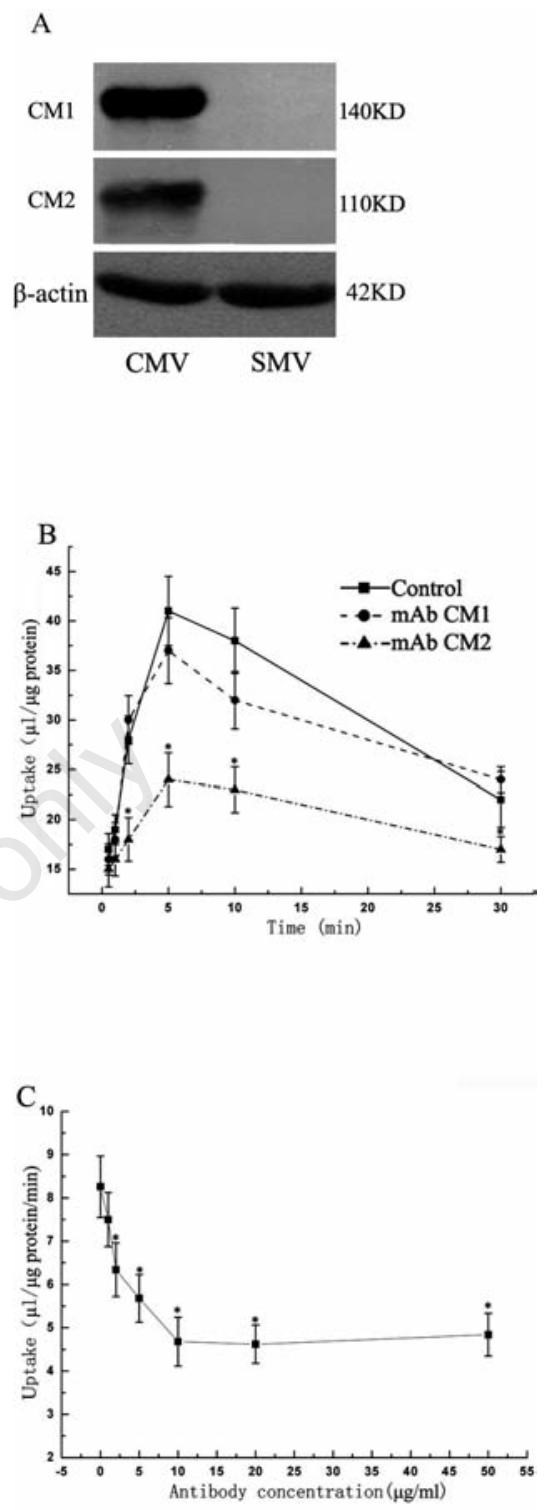

Figure 4. Identification and characterization of CM1 and CM2 antigens. A) CM1 and CM2 antigens by western blot analysis; molecular mass of CM1 and CM2 antigens were approximately $\mathrm{Mr} 140 \mathrm{kDa}$ and Mr $110 \mathrm{kDa}$ respectively; either CM1 or CM2 antigens in rat hepatocyte CMVs was much more than that in hepatocyte SMVs. B) Effect on ATP-dependent E217 $\beta$ G uptake activities of CMVs of CM1 or CM2 $(10 \mu \mathrm{g} / \mathrm{mL})$ for different incubated time $(0,5,10,15,20,25,30 \mathrm{~min})$; CM2 inhibited most E217 $\beta$ G uptake activities of CMVs at 5 min. C) Effect on ATP-dependent E217 BG uptake activities of CMVs of CM2 with different concentration of antibody $(1,2,5,10,20,50 \mu \mathrm{g} / \mathrm{mL})$ when incubated for $5 \mathrm{~min}$; $\mathrm{CM} 2$ inhibited E217 $\beta$ G uptake of CMVs in a concentration-dependent manner and saturatus level was obtained at about $10 \mu \mathrm{g} / \mathrm{mL}$. Points represented the average ATPdependent uptake, which subtracted that in the absence of ATP; bars represented the SD. Statistics were performed by Student's $t$-test and significance $\left(^{*}\right)$ means $P<0.05$. 


\section{Discussion}

The polarized molecules predominately distributing at hepatocyte canalicular surface play a vital role in disclosing the process of bile formation and etiopathogenisis of cholestatic live diseases. Therefore, it is important to find novel polarized molecules on hepatocyte canalicular membrane. In our experiments, we utilized hybridoma technique and obtained 46 stains of monoclonal antibodies against rat hepatocyte CMVs, two of which, CM1 and CM2, were confirmed to predominately localize to hepatocyte canalicular membrane. According to their distinct cell-specific distribution, molecular mass and blocking activity of E217 $\beta$ G uptake, it was speculated that CM1 and CM2 antigens could be different polarized molecules on hepatocyte canalicular membrane.

The polarized molecules on hepatocyte canalicular membrane belong to plasma membrane (PM) proteins, which were often difficult to analysis in proteomics studies, due to their low abundant, insoluble, high molecular mass and complicated post-translational modification. Gelbased proteomics strategies, multidimensional liquid chromatography techniques coupled with tandem mass spectrometry (LC-MS/MS), subtractive cDNA strategy and differential display technique were common approaches for studying PM proteomics, ${ }^{16}$ but each had different disadvan- tages. For example, Gel-based proteomics strategies had major limitations of poor sensitivity and narrow dynamic range to hydrophobic PM proteins. ${ }^{17}$ LC-MS/MS was a high-throught screening approach for efficient solubilization of hydrophobic proteins utilizing SDS, but had difficulties for comparative quantitation between biological samples and needing much experiments with morphological and biochemical methods to confirm the results. ${ }^{18}$ Subtractive cDNA strategy and differential display technique could analyze the differentially expressed proteins but need phagehost biology and successful phage display. ${ }^{19}$ The hybridoma approach was proved to be a powerful approach to screening PM proteins, which allowed us to use heterogeneous immunogens to obtain the most interesting antigens by further functional screening..$^{20,21}$ For example, rat hepatocyte plasma membrane proteins such as B10 and H4 were found using hybridoma technology and subsequently identified. ${ }^{22,23}$ In our studies, we used subcellular fractions to aggregate the abundance of rat canalicular membrane proteins as heterogeneous immunogens. Meanwhile, we could also use the obtained mAbs to further screen our interesting proteins with morphological and functional methods.

MRP2 was identified to be the only known glucuronide transporter on the hepatocyte canalicular membrane, while many studies illustrated other unknown transporters should also be responsible for the biliary excretion of glucuronide conjugate. Kouzuki et al. found that indomethacin glucuronide transport clearance across the bile canalicular membrane in hepa Eisai hyperbilirubinemic rats (EHBR) with MRP2 function hereditarily defective was approximately $50 \%$ that in Sprague-Dawley rats (SDRs). ${ }^{24}$ Nishino et al. confirmed that no significant difference was observed in the biliary excretion of BIBR 277 glucuronide between SDRs and EHBR, although the plasma disappearance of BIBR 277 glucuronide was delayed in EHBR. ${ }^{25}$ In our study, we found that CM2 antigen could inhibit ATPdependent glucuronide uptake of CMVs (Figure 4B) and contribute to the glucuronide excretion.

As previous studies showed, almost all transporters on hepatocyte canalicular membrane such as bile salt-export pump (BSEP), multidrug resistance-1 (MDR1), multidrug resistance-3 (MDR3), MRP2, and breast cancer resistance protein (BCRP) belong to ATP binding cassette (ABC) superfamily proteins. ${ }^{26-28}$ Since the structure of $\mathrm{ABC}$ transporters were classified into seven transmembrane proteins, their molecular mass were much more than $140 \mathrm{KD}$ except for $\mathrm{BCRP}^{29}$ a $72 \mathrm{kDa}$ half-transporter protein, which was believed to homodimerize, or possibly oligomerize in order to function. It should be noted that the molecular mass of CM2 antigen was just $110 \mathrm{kDa}$, much less than those of classic $\mathrm{ABC}$ transporters. Thus, it could be assumed that

Table 1. The known polarized molecules at the canalicular membrane of hepatocytes.

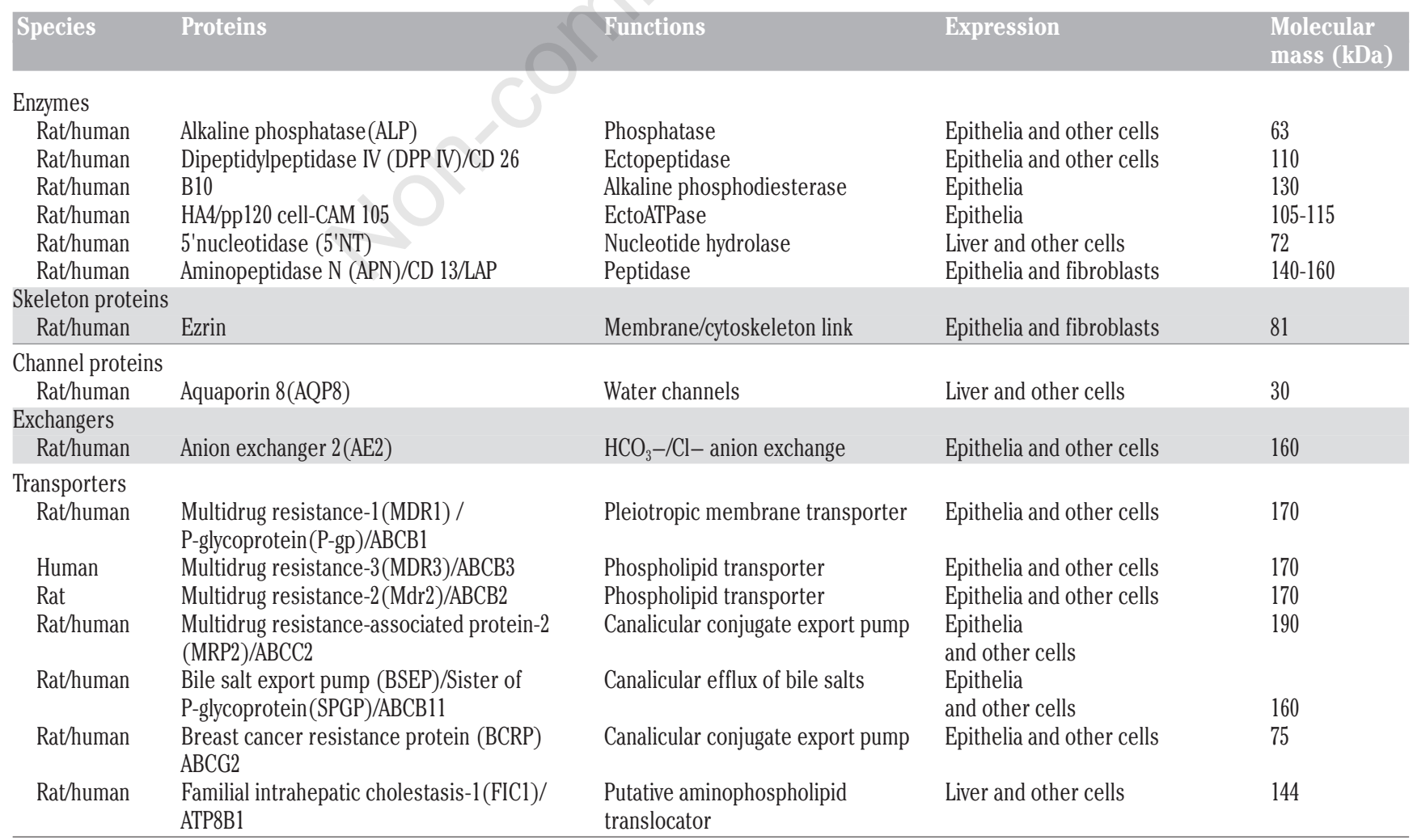


CM2 antigen should not belong to $\mathrm{ABC}$ transporter and could indirectly participate in glucuronide transport as $\mathrm{ABC}$ transporters interacting proteins.

In all the known polarized molecules at hepatocyte canalicular membrane (Table 1), the molecular weight and distribution of CM2 antigen were nearly similar with those of dipeptidylpeptidase IV (DPP-IV) and cell cell-adhesion molecule (cellCAM 105). ${ }^{30-33}$ However, DPP-IV, cell-CAM 105 and CM2 antigen actually displayed different characters in some details. First, DPP-IV was positive in the luminal portion of interlobular bile ducts and glomeruli, while CM2 antigen was negative (Figure $1 \mathrm{D}, \mathrm{F}$ ). Second, CM2 antigen was positive at vascular endothelial cells (Figure 1F), while cell-CAM 105 was not. In addition, although cellCAM 105 was identified to be an ATP-dependent taurocholate transporter, CM2 could partially inhibit ATP-dependent glucuronide uptake of CMVs (Figure 4B). Therefore, it suggested that CM2 antigen be neither DPP-IV nor cell-CAM 105.

Taken together, CM2 antigen predominately distributed at rat hepatocyte canalicular membrane and might be a potential novel molecule participating in glucuronide transport on rat hepatocyte canalicular membrane.

\section{References}

1. Wisher MH, Evans WH. Functional polarity of the rat hepatocyte surface membrane. Isolation and characterization of plasmamembrane subfractions from the blood-sinusoidal, bile-canalicular and contiguous surfaces of the hepatocyte. Biochem $\mathrm{J}$ 1975;146:375-88.

2. Diaz GJ. Basolateral and canalicular transport of xenobiotics in the hepatocyte: A review. Cytotechnology 2000;34:225-35.

3. Roman LM, Hubbard AL. A domain-specific marker for the hepatocyte plasma membrane: localization of leucine aminopeptidase to the bile canalicular domain. J Cell Biol 1983;96: 1548-58.

4. De Broe ME, Roels F, Nouwen EJ, Claeys L, Wieme RJ. Liver plasma membrane: the source of high molecular weight alkaline phosphatase in human serum. Hepatology 1985;5:118-28.

5. Kartenbeck J, Leuschner U, Mayer R, Keppler D. Absence of the canalicular isoform of the MRP gene-encoded conjugate export pump from the hepatocytes in Dubin-Johnson syndrome. Hepatology 1996;23:1061-6.

6. Paulusma CC, Kool M, Bosma PJ, Scheffer GL, ter Borg F, Scheper RJ, et al. A mutation in the human canalicular multispecific organic anion transporter gene causes the Dubin-Johnson syndrome. Hepatology 1997;25:1539-42.

7. Wada M, Toh S, Taniguchi K, Nakamura T,
Uchiumi T, Kohno K, et al. Mutations in the canilicular multispecific organic anion transporter (cMOAT) gene, a novel ABC transporter, in patients with hyperbilirubinemia II/Dubin-Johnson syndrome. Hum Mol Genet 1998;7:203-7.

8. Bull LN, van Eijk MJ, Pawlikowska L, DeYoung JA, Juijn JA, Liao M, et al. A gene encoding a P-type ATPase mutated in two forms of hereditary cholestasis. Nat Genet 1998;18:219-24.

9. Solis Herruzo JA, Solis Munoz P, Munoz Yague T. The pathogenesis of primary biliary cirrhosis. Rev Esp Enferm Dig 2009;101:413-23.

10. Tietz PS, Holman RT, Miller LJ, LaRusso NF. Isolation and characterization of rat cholangiocyte vesicles enriched in apical or basolateral plasma membrane domains. Biochemistry 1995;34:15436-43.

11. Mazzone A, Tietz P, Jefferson J, Pagano R, LaRusso NF. Isolation and characterization of lipid microdomains from apical and basolateral plasma membranes of rat hepatocytes. Hepatology 2006;43:287-96.

12. Wang JB, Zhou XM, Liu JM, Yan L, Liang J, Zhai HH, et al. Fractionate and collect hepatocyte canalicular membrane vesicles of rats and study their transportation functions in vitro. [in Chinese]. Chin J Hepatol 2007;15: 617-8.

13. Liu JP, Liu YY, Wong-Riley MT, Liu HL, Ju G. A group of neurokinin-1 receptor-immunoreactive neurons expressing phospho-extracellular signal-regulated protein kinases in the pre-Botzinger complex of rats. J Neurosci Res 2005;80:260-7.

14. Huang L, Smit JW, Meijer DK, Vore M. Mrp2 is essential for estradiol-17beta(beta-D-glucuronide)-induced cholestasis in rats. Hepatology 2000;32:66-72.

15. Rocken C, Licht J, Roessner A, Carl-McGrath S. Canalicular immunostaining of aminopeptidase N (CD13) as a diagnostic marker for hepatocellular carcinoma. J Clin Pathol 2005;58:1069-75.

16. Scherer PE, Bickel PE, Kotler M, Lodish HF. Cloning of cell-specific secreted and surface proteins by subtractive antibody screening. Nat Biotechnol 1998;16:581-6.

17. Chambers G, Lawrie L, Cash P, Murray GI. Proteomics: a new approach to the study of disease. J Pathol 2000;192:280-8.

18. Aebersold R, Mann M. Mass spectrometrybased proteomics. Nature 2003;422:198-207.

19. Scherer PE, Bickel PE, Kotler M, Lodish HF. Cloning of cell-specific secreted and surface proteins by subtractive antibody screening. Nat Biotechnol 1998;16:581-6.

20. Stern M, Herrmann R. Overview of monoclonal antibodies in cancer therapy: present and promise. Crit Rev Oncol Hematol 2005;54:11-29.

21. Steinitz M. Three decades of human monoclonal antibodies: past, present and future developments. Hum Antibodies 2009;18:1-10.

22. Meerson NR, Delautier D, Durand-Schneider AM, Moreau A, Schilsky ML, Sternlieb I, et al. Identification of B10, an alkaline phosphodiesterase of the apical plasma membrane of hepatocytes and biliary cells, in rat serum: increased levels following bile duct ligation and during the development of cholangiocarcinoma. Hepatology 1998;27:563-8.

23. Krause P, Rave-Frank M, Wolff HA, Becker H, Christiansen H, Koenig S. Liver sinusoidal endothelial and biliary cell repopulation following irradiation and partial hepatectomy. World J Gastroenterol 2010;16:3928-35.

24. Kouzuki H, Suzuki H, Sugiyama Y. Pharmacokinetic study of the hepatobiliary transport of indomethacin. Pharm Res 2000; 17:432-8.

25. Nishino A, Kato Y, Igarashi T, Sugiyama Y. Both cMOAT/MRP2 and another unknown transporter(s) are responsible for the biliary excretion of glucuronide conjugate of the nonpeptide angiotensin II antagonist, telmisaltan. Drug Metab Dispos 2000;28: 1146-8.

26. Dean M. ABC Transporters, Drug Resistance, and Cancer Stem Cells. J Mammary Gland Biol Neoplasia 2009;14:3-9.

27. Kos V, Ford R. The ATP-binding cassette family: a structural perspective. Cell Mol Life Sci 2009;66:3111-26.

28. Sauvage V, Aubert D, Escotte-Binet S, Villena I. The role of ATP-binding cassette (ABC) proteins in protozoan parasites. Mol Biochem Parasitol 2009;167:81-94.

29. Uggla B, Ståhl E, Wågsäter D, Paul C, Karlsson MG, Sirsjö A, et al. BCRP mRNA expression v. clinical outcome in 40 adult AML patients. Leuk Res 2005;29:141-6.

30. Becker A, Lucka L, Kilian C, Kannicht C, Reutter W. Characterisation of the ATPdependent taurocholate-carrier protein (gp110) of the hepatocyte canalicular membrane. Eur J Biochem 1993;214:539-48.

31. Iwaki-Egawa S, Watanabe Y, Fujimoto Y. Identification of a rat liver dipeptidyl aminopeptidase IV with a liver plasma membrane glycoprotein (gp110) A study using dipeptidyl aminopeptidase IV-deficient rats. FEBS Lett 1991;286:167-70.

32. Lucka L, Cichocka I, Bäumler K, Bechler K, Reutter W. A Short Isoform of Carcinoembryonic-Antigen-Related Rat Liver CellCell Adhesion Molecule (C-CAM/gp110) Mediates Intercellular Adhesion. Eur J Biochem 1995;234:527-35.

33. McCaughan GW, Wickson JE, Creswick PF, Gorrell MD. Identification of the bile canalicular cell surface molecule GP110 as the ectopeptidase dipeptidyl peptidase IV: an analysis by tissue distribution, purification and N-terminal amino acid sequence. Hepatology 1990;11:534-44. 